\title{
"Nueva Epidemiología Psiquiátrica". Undécimo Simposio de la Sección de la AEP sobre Epidemiología y Psiquiatría Social
}

El Simposio se celebró los días 17-20 de abril de 2002 en Aarhus, Dinamarca, en el maravilloso Centro de Congresos recién construido. Hubo 200 participantes, todos muy activos y muchos de ellos seleccionados entre los colegas más jóvenes de toda Europa.

El título para el Simposio era "Nueva Epidemiología Psiquiátrica". Esta moneda tiene dos caras. Una es la intención de presentar nuevas tendencias en epidemiología dentro de la psicofarmacoepidemiología, la epidemiología de búsqueda etiológica, la epidemiología de la salud pública, la epidemiología genética, etc. El otro lado de la moneda es una ambición de seleccionar colegas jóvenes para la red de epidemiología y psiquiatría social europeas. Los organizadores mismos piensan que la Sección tuvo éxito en eso.

Como se mencionaba, participaron unos 200 colegas de toda Europa, junto con representantes de Canadá, EE.UU., Brasil y Australia. Algunos colegas más experimentados se registraron con 8-10 jóvenes de su grupo de investigación. En particular, advertimos grandes delegaciones de Gothenburg en Suecia, Budapest en Hungría y Maastricht en los Países Bajos.

Recibimos 175 resúmenes. Se pueden leer en el Suplemento de Acta Psychiatrica Scandinavica 2002; 411: 105.

Con respecto a las presentaciones, teníamos dos prioridades. Una era dar a los plenarios espacios para los colegas jóvenes y al mismo tiempo animar a los colegas más experimentados, miembros de la junta y otros a participar como contertulios, líderes de talleres, profesores de curso, etc. También nos preocupamos de que los colegas jóvenes fueran Presidentes/Copresidentes junto con los colegas más experimentados. La segunda prioridad se dio a las sesiones de pósters. Los pósters se presentaron agrupados por temas y hubo buena asistencia a las sesiones. Dos miembros de la junta, Michele Tansella de Verona, y Graham Thornicroft, de Londres, evaluaron todos los pósters, seleccionaron el primero, segundo y tercer premios de las dos sesiones de pósters y presidieron con gran competencia y provisión de apoyo la sesión de premios de los pósters el último día del congreso. Cada uno de los ganadores de los premios ofreció una presentación de 5 minutos de su investigación. Esta sesión de premios tuvo buena acogida por la audiencia, los colegas jóvenes especialmente estuvieron presentes en gran cantidad.

La conferencia de la ceremonia de premios la dictó la Dra. Mirilla Ruggeri, de Verona. El título para su conferencia fue "Predictores transversales y longitudinales de la calidad subjetiva y objetiva de vida en los pacientes psiquiátricos comunitarios."

Conceder los premios, circular los resúmenes mundialmente y distribuirlos a todos los participantes en un suplemento de Acta Psychiatrica Scandinavica (total de copias: 2000) fue posible sólo por una generosa beca sin limitaciones de Wyeth Denmark.

El elevado nivel de calidad del congreso junto con la reducida tarifa fue posible a causa del generoso apoyo de: Pfizer ApS, Janssen-Cilarg A/S, Organon AS, Pharmacia \& Upjohn AS, Wyeth, Eli Lyilly Danmark A/S y GlaxoSmithKline.

Además, Pfizer ApS patrocinó al orador invitado Nicholas Moore, de Burdeos, que presentó la psicofarmacoepidemiología en nuestra Sección con la conferencia plenaria titulada "Ejemplos de uso de la psicofarmacoepidemiología".

A partir de un taller acerca de la investigación epidemiológica psiquiátrica en los países de la antigua Europa del Este, formamos un grupo de trabajo bajo la Sección de la AEP sobre Epidemiología y Psiquiatría Social. Este grupo de trabajo tiene como propósito principal promover y apoyar la investigación psiquiátrica epidemiológica en los antiguos países del Este europeo. Los principios básicos son que los colegas de Europa del Este deben hacer este trabajo según sus propios criterios, pudiendo recabar ayuda de otros colegas en la Sección cuando sea necesario y, en conjunto, integrar la investigación en una red europea que cubra toda la región europea. Monika Kovacs de Budapest es la coordinadora de este grupo, llamado Grupo de la AEP de abril de 2002. No dude en contactar con Monika Kovacs (e-mail: kovmon@net.sote.hu).

Una noche, el congreso fue invitado por el alcalde del Condado de Aarhus a una recepción en el Hospital Psiquiátrico en Aarhus, en celebración de su 150 aniversario. Otra noche nos invitó al Ayuntamiento el alcalde de la Ciudad de Aarhus, y la última noche tuvi- 
mos una cena del congreso en la Mansión Varna que los jóvenes invitados hicieron alegre.

Mantendremos los principios que formaron la base del Simposio de Aarhus cuando celebremos el $12^{\circ}$ Simposio de la Sección de la AEP sobre Epidemiología y Psiquiatría Social en Mannheim, Alemania, los días 23-26 de junio de 2004. Para información adicio- nal acerca del Simposio de Mannheim, no dude en contactar con el presidente del comité organizador, Siegfried Weyerer (e-mail: weyerer@as200.zi-mannheim.de).

Pobl. Munk-Jørgensen,

Presidente, Sección sobre Epidemiología y Psiquiatría Social. 